\title{
The Role of the Family in Preventing Relapse of Schizophrenia Patient
}

\author{
Mamnuah Mamnuah* \\ Department of Nursing Science, Universitas Aisyiyah Yogyakarta, Yogyakarta, Indonesia
}

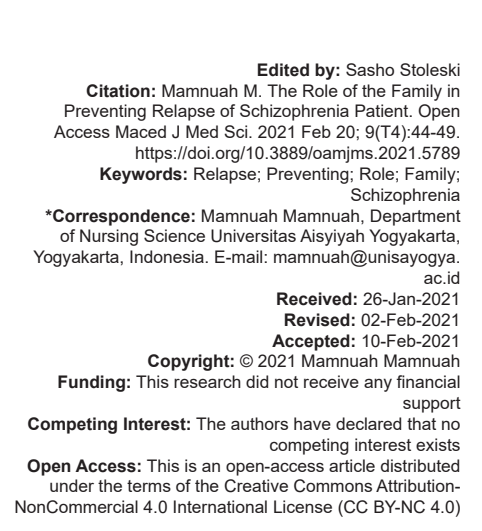

\section{Abstract}

BACKGROUND: The relapse rate of schizophrenia patients is still high. The family has an important role in helping schizophrenia patients to avoid recurrence.

AIM: This study aimed to describe the role of the family in preventing relapse schizophrenia patients.

METHODS: The research used a qualitative design with a phenomenology approach. The sample consisted of 12 families who had schizophrenic patients. The samples were obtained by purposive sampling technique. The data were collected by interview and using field notes, then analyzed by Colaizzi technique.

RESULTS: The results showed that the role of the family in preventing the recurrence of schizophrenia patients was of four themes, namely, acceptance, assistance, hope, and communication from the family.

CONCLUSION: There are four roles of the family to prevent a patient's recurrence. The government needs to pay attention to the families of schizophrenia patients.

\section{Introduction}

The prevalence rate of schizophrenia is around $1 \%$ of all world population, of all schizophrenics, there are $15 \%$ of children whose parents are schizophrenic and $35 \%$ of children whose parents both suffer from schizophrenia [1]. The rate of mental disorders in Yogyakarta is higher than the figure in Indonesia, which is $2.7 / 1000$, exceeding the national figure, which is $1.7 / 1000$ [2]. The recurrence rate of mental patients is still high. The results of a previous study of the recurrence rate of psychiatric patients found that $70.5 \%$ of schizophrenics experienced relapse within ten years with a mean relapse of 1.9 years [3]. The results of the study [4] on the history of recurrence of schizophrenia patients at Dr. Sardjito obtained the results that from 47 post-hospitalized patients at Dr. Sardjito in May 2007-May 2008, there were 26 people (55.3\%) who experienced recurrences. According to Liberman and Kopelowicz [5], one of the criteria for recovery is no recurrence for $2-5$ years.

According to Newell and Gournay [6], the existence of family members who experience schizophrenia is a burden on the family and the health system. Mental health problems can cause global economic losses of up to US \$ 16 trillion between 2010 and 2030 [7]. Research by Tamizi et al. [8] explains that the objective burden felt by families while caring for schizophrenic patients is heavy caregiver involvement and challenges to the health-care system. Research by Aubeeluck and Luximon-Ramma [9] explains that the presence of schizophrenic patients at home makes families worry about their own safety when patients commit violence and avoid large social events with their relatives. The family also complained of financial difficulties.

Relapse of patients can be influenced by family emotions, such as in Fadli and Mitra [10] study of high family emotional expressions, such as hostility and criticism, making patients relapse more frequently than families with low emotional expressions. Family has an important role to play in helping schizophrenic patients from relapse. Schizophrenic patients are a burden for families who care for them, as research by Suryani et al. [11] obtained data that as many as 42 respondents $(42 \%)$ had moderate-to-severe levels of burden, 23 respondents (23\%) had very heavy levels of burden, and 3 respondents (3\%) with very heavy loads and heavy loads. Research [12] also said that the family burden is heavy in caring for schizophrenic patients and affects their coping strategies. Reference [13] explained that caring for family members who have mental disorders has two important things, namely, 
the burden of care and stigma. The care burden felt by the family is confusion about illness, emotional, physical, time, financial, and social burdens, which lead to a decline in the quality of family life. Families also experience a stigma called labeling, stereotyping, separation, and discrimination. Stigma means that the family faces psychological, social, and intrapersonal consequences. This decreases the quality of family life and family functionality, and there are opportunities that have a negative impact on family resilience.

Several studies that have been researched previously still focus on the burden of families in caring for mental patients. Not many studies have explored the role of the family in preventing recurrence in schizophrenic patients. Therefore, this paper will present and discuss the role of the family in preventing the recurrence of schizophrenia patients with a qualitative approach. This study aims to obtain an overview of the role of the family in preventing the recurrence of schizophrenic patients.

\section{Methods}

This study used a qualitative design with a phenomenological approach. The sampling technique was purposive sampling. The sample size is 12 families who have treated schizophrenia patients for at least 3 years. Data were collected through in-depth interviews once. The researcher also made field notes to describe situations that were not recorded by the recording device during the interview process. Interviews were recorded based on participant consent. Data validation was done by triangulation of methods, triangulation of analysis, and validation with participants. Data analysis using Colaizzi. Data analysis was carried out by making transcripts, reading repeatedly the results of interview transcripts and field notes, identifying meaningful quotations and statements, creating categories, and determining subthemes and main themes. The process of data collection was approved by the Medical and Health Research Ethics Committee of the Faculty of Medicine, Public Health and Nursing, Universitas Gadjah Mada, Indonesia, with the number KE/FK/1269/ EC/2016.

\section{Results}

Participants were families caring for 12 people with schizophrenia mental disorders, consisting of eight females and four males. The youngest is 37 year old and the oldest is 75 year old. The lowest level of family education is not in school and the highest is bachelor.
Family work consists of housewives, farm laborers, self-employed, and retired civil servants. Based on the characteristics of the religion adopted, the participants consisted of 11 people who are Muslims and one person who is Catholic. The shortest length of care was 3 years and the longest was 31 years. Participant data are shown in Table 1.

Table 1: Characteristics of participants

\begin{tabular}{llllll}
\hline Initial & Age (years old) & Sex & Education & Job & Religion \\
\hline P1 & 66 & Female & Primary school & Farmworker & Moslem \\
P2 & 75 & Female & Junior high school & Housewife & Moslem \\
P3 & 60 & Female & Primary school & Housewife & Moslem \\
P4 & 57 & Male & Senior high school & Farmworker & Moslem \\
P5 & 37 & Female & Primary school & Housewife & Moslem \\
P6 & 57 & Female & Junior high school & Seller & Moslem \\
P7 & 67 & Female & No school & Farmworker & Moslem \\
P8 & 51 & Male & No school & Laborer & Moslem \\
P9 & 51 & Female & Senior high school & Seller & Moslem \\
P10 & 63 & Male & Senior high school & Retired & Moslem \\
P11 & 40 & Male & Primary school & Farmworker & Moslem \\
P12 & 58 & Female & Bachelor & Housewife & Catholic \\
\hline
\end{tabular}

There are four themes to the role of the family in helping schizophrenia patients to avoid relapse, namely, acceptance from the family, assistance from the family, hope, and communication. Each of them will be described as follows:

\section{Family acceptance}

Families who accept the condition of a schizophrenic patient are those who have positive feelings toward the patient and a sense of responsibility toward the patient. Family acceptance of patients can be seen in the following expressions:

"I don't have any shame thoughts. I took her to the doctor in Yogya many times and it cost a lot of money, this is not a problem for me, because of my responsibility as a father" (P10).

"I've never been ashamed, I don't feel that it's a curse. Patients need love from those around them, especially family. Patients want to be understood, not just scolded. It is understood that schizophrenia is like that, if the family has a feeling of love, they will be taken to a psychiatrist and then invited to a healthy lifestyle and do activities" (P12).

\section{Family assistance}

Families play a role in accompanying patients to prevent a recurrence. Family assistance is carried out when seeking treatment, administering patient medication, and helping outreach in the community, as described as follows:

"Go to a shaman, many times, then recently to Grhasia (Mental Hospital). I have visited the shaman 7 times" (P1).

"He sometimes forgets at night, then I prepare (medicine), prepare a drink, prepare the medicine to drink before sleeping. Sometimes, he won't take (medicine), later. Finally, I took the medicine, walked (to the community health center)" (P5). 
"I invited him to participate in social activities, in religious activities, in the community, but before that, I first gathered strength with community leaders, neighbors, urban villages, so I developed good relationships so that if my younger sibling, my family were there, they would understand. With prayer, medicine, and work, it is hoped that his stable period will belong" (P12).

Families also provide work assistance to patients by taking them to the fields, transporting sand, and providing skills training by inviting the trainer to the house, as described as follows:

"He hauled sand, went to the rice fields, invited to the rice fields too" (P5). The results of participant observation indicate the location of sand transport.

"So I made a schedule for them, I put it in a strategic place so I can control, they can also see. So according to their talents and interests, from waking up that morning they already have activities, so if they match their talents they will be happy. I am starting something new, there is no link anywhere, calling the teacher costs money" (P12).

The family plays a role in assisting patients in participating in religious activities in their village, as described as follows:

"He is willing to pray Friday, to pray together, Friday night dhikr" (P5).

"Because I am Catholic, teaching religion is not just going to church every Sunday, praying before eating, praying before bed. But I invite them to feel that God really exists and can be felt in their lives" (P12).

\section{Hope}

The family helps prevent recurrence of the patient by having a hope of recovery for the patient, as expressed as follows:

"Can (recover). I try my best" (P10).

"For the husband's recovery" (P5).

The family also believes that schizophrenic patients can recover with their ability to manage the patient's psychology himself, as stated as follows:

"Yes, he can (recover 100\%). There are stages, he must be able to reason. Maybe by sharing feelings, sharing experiences so that the medicine is actually in itself" (P10).

Families who have no hope of a patient's recovery, the role of the family to help prevent patients from relapse is very small, as is expressed as follows:

"Hopeless, tired, our family has been tired for a long time, the mother has also not paid attention, just been left alone. The important thing is that she is given food, drink, and clothes" (P11).

"I'm tired, I let it now" (P2).

\section{Family communication}

Family communication has a role in preventing relapse in schizophrenic patients. The family communicates with the patient in a gentle, soft, choice of words that do not offend the patient, and is patient, as expressed as follows:

"Tell him about something right, right work, right talk. Tells the correct behavior but slowly" (P2).

"We have to speak subtly, we must not speak harshly, we must be patient. If I ask anything, I have to slow down" (P5).

"Communication is not just communication, there are communication techniques as well as how to communicate effectively with them. That's what I do" (P12).

\section{Discussion}

The results showed that there were four themes of the role of the family in preventing recurrence of schizophrenia, namely, acceptance, assistance, hope, and communication. Acceptance from the family really helps patients so that they do not easily relapse and live in society. Family acceptance is characterized by no shame for the family toward the patient. Families also have the readiness to seek treatment so that patients do not easily experience recurrences. Family acceptance of schizophrenic patients is very important for patients in accordance with the opinion of Dorian et al. [14] that family acceptance is the involvement of families with schizophrenic patients and does not have high expectations for changes in patient behavior. Acceptance contains three aspects, namely, general patient acceptance, integrated detachment (discussion of a problem that is not blaming but involves), and low adversarial responses to patient behavior (e.g., criticism and demanding change). Families with low emotional expressions can accept the patient's condition.

Mental disorders benefit family members who will become a burden on the family, both objective and objective burdens. The objective burden of patient behavior, role performance, support needs, and financial costs are borne by the family. The burden is related to the feeling of being overwhelmed, such as feelings of grief, pain, helplessness, and fear of recurrence that represent the patient. The stigma of existence is also a burden on the family. According to Stuart [15], families need adjustments when they have family members who have mental disorders. Matters affecting the adjustment process are family resources such as parents' understanding of illness, financial availability, availability of time and energy, and the ability to provide ongoing support. Soundy et al. [16] stated that the existence of a close relationship between the family and the patient, 
a sense of belonging, and family responsibility towards the patient will support patient recovery.

The results of this study also explain the responsibility of parents toward their children to help patients not to recur. Various attempts have been made by the family as a sense of responsibility towards family members who have mental disorders. The forms of responsibility carried out by the family are: Taking the patient to the hospital, covering all medical expenses, and meeting all the patient's needs. Before the national health insurance, families used personal costs to seek treatment for patients. The cost used is large enough to even spend family savings. After there is national health insurance, medical expenses are guaranteed by the government so that the patient's treatment is not interrupted. This condition is very helpful in reducing patient recurrence.

Family assistance to prevent patient recurrence is done by managing the patient's medication, socializing, working, and meeting the patient's spiritual needs. This is in accordance with the results of research by Tamizi et al. [8] which explains that families assist patients in meeting the patient's self-needs, treatment, and prevention of violence in patients. Families help patients assist socialization in the community by asking permission from other residents so that patients can participate in community activities. Families will protect patients so that violence does not occur against family members who have mental disorders. The family maintains good relations with the surrounding community so that if something happens to the patient, the neighbors will immediately provide the necessary assistance. Reference Jose et al. [17] explained that to help patients heal, four categories are needed, namely, self-orientation, family orientation, social orientation, and disease orientation. Family orientation is explained as a condition that healing is closely related to family, interacting, working, and living together with the family. Families play a role in helping the patient's next life. The study by Febriana et al. [18] explains the importance of family support in the treatment of schizophrenia patients to prevent relapse. The results of this study illustrate the role of the family in the treatment of patients by taking the patient to the health service for routine control. Sometimes, the family also fetches the patient's medicine at the public health center. The family does not feel burdened doing this task because of the great desire that family members who experience mental disorders do not recur easily and even hope to recover completely. The family helps prepare and remind the patient to take the medicine.

Families also play a mentoring role for outreach in the community. The results of this study are consistent with the research of Pahwa et al. [19] that community integration is important in the patient's healing process. There are three dimensions of community integration, namely, physical, psychological, and social integration [19]. Families help patients meet their physical, psychological, and social needs. The patient's nutritional needs are met by the family. The family also keeps the patient psychologically so they are not easily offended. Families help patients with social needs by involving patients in community activities such as social gatherings, community service, and other social activities.

Other studies suggest that community integration is important in the healing process and is a marker of patient well-being [20]. The patient tries to let go of his sick role and builds a meaningful personal identity so that he can carry out his role in the community [20]. Reference Sarwono and Subandi [21] explained that aspects of cognition, affection, and conation mutually support the quality of patient reintegration to society. The higher a person's social class, the lower the process of psychosis patient reintegration into society, because of the teachings of high weight seeds which become a psychological barrier to return to society. Early phase psychosis patients still easily get various types of community support, in the form of appreciation, acceptance, information, social networks, and instrumental support. People who live in a traditional economic system are still tolerant enough to provide support, cooperation, tolerant, and help each other.

The hope that the family has will help the family to play a role in preventing recurrence of the patient. According to Liberman [22], patients with mental disorders can return to a normal life in society, one of which is influenced by hope or the hope of getting better. Families who have hopes for patients to recover will play a lot to help patients so they do not experience recurrences. In contrast to families who do not have hope of a patient's recovery, the family tends to leave the patient alone, not doing much to help prevent the patient's recurrence. The hope that the family has will help the family identify the need to avoid recurrence, namely, by managing patient medication, assisting in socialization, and engaging in community activities. One of the nursing interventions is to help patients adhere to taking medication with acceptance and commitment therapy. One of the studies on this therapy was conducted by Komala et al. [23] for schizophrenic patients, the results are effective in increasing insight, reducing signs and symptoms of violent behavior, and increasing the patient's ability to control violent behavior. Having hope for the future can improve the quality of life through enthusiasm and therapeutic relationships. Hope can help motivate someone to change and actively participate in clinical services or self-help. The subjective experience of empowerment and hope that continues to grow after achieving recovery can strengthen and prevent individuals from relapse [5]. Hope is not only owned by the patient but also by the family who cares for him. This study illustrates that there is a family expectation of a patient's recovery to make the family struggle to help the patient remain stable and 
not easily relapse. The family never complains while accompanying the patient because they believe that the patient will be given a cure. In contrast to families who do not have hope for a patient's recovery, the family does not provide full support for the patient's recovery. This condition occurs because the family feels hopeless and tired of caring for the patient because after a long period of treatment, they have not shown positive changes.

One of the results of research that explores hope is a study conducted by Noh et al. [24] entitled hope from the perspective of people with schizophrenia (Korea). The research found three themes, namely, the meaning of hope, the goals of hope, and the sources of hope. This study explores patient expectations in contrast to this study which explores family expectations. The existence of hope from the family helps prevent a patient's recurrence. The family has the belief to heal their family members who have mental disorders. This belief makes families excited to seek treatment. Efforts to seek medical treatment from families are not always in health services, but families have also sought treatment from smart people/traditional healers. Many times, the family came to the dukun, but the results were still there, there was no change. Finally, the family came to health services and received regular treatment. Often, there is a delay in handling mental patients in the community because the search for treatment is not initiated at the health service.

Reference Noh et al. [16] explained that the hopelessness experienced by families will hinder the recovery of schizophrenia patients. This study also found that there were families who felt hopeless and had no hope of the patient's recovery. When the family has no hope, the role of the family is also minimal. This condition also causes shackling to schizophrenic patients, even patients are not treated well by their families. Families can commit violence against these patients. For this reason, it is necessary to maintain family expectations for schizophrenia patients so that the family continues to provide optimal support in preventing patient recurrence.

High family emotional expression makes patients relapse more frequently than families with low emotional expression. Hostility and criticism are high emotional expressions [10]; [25]. This study is in line with the results of this study which explains that schizophrenic patients need polite and effective communication so they do not easily relapse. The family chooses words that do not offend the patient, are delivered at the right time, and are conveyed in a low tone. In accordance with the research of Rashidpour et al. [26], emotional criticism and involvement are significant predictors of patient recurrence. The more emotions expressed in family members, the more frequent relapses were seen among patients. However, the relationship between the emotions expressed and the frequency of relapses was not influenced by the sex of the family members or their relationship with the patient. In addition, more educated family members have lower emotions toward patients because of their greater awareness. The results of this study illustrate that family acceptance of schizophrenic patients makes the family not feel ashamed to have family members who have mental disorders. This condition makes the family learn how to understand the patient, namely, by observing the cause of the patient's relapse. The family gradually observes the patient's behavior, how to communicate with the patient, and how to solve the patient's problems. The family also studies interactions to which the patient is offended as much as possible. The choice of words when communicating with patients is also important so as not to upset the patient. The arrival of another family member who does not live in the same house is also a family concern because it is a possible cause of stressors for the patient.

\section{Conclusion}

There are four roles of the family to prevent a patient's recurrence, namely, family acceptance, family assistance, hope, and communication. Family acceptance is characterized by the family not feeling ashamed of the patient and not demanding too highly of the patient's behavior change. The role of the family in preventing recurrence by assisting is marked by assisting patients in medication, socialization, and work. The hope that the family has for the patient's recovery will help prevent the patient's recurrence. Communication between families and patients should be done with empathy, soft language, and be done with great patience.

It is hoped that the government will pay attention to families who have family members who have mental disorders. Family therapy can be done to help the family's ability to prevent the recurrence of the patient. Future researchers are expected to develop further research on family therapy to improve the ability of families to care for schizophrenia patients.

\section{References}

1. Videbeck SL. Psychiatric Mental Health Nursing. $5^{\text {th }}$ ed Philadelphia, PA: Lippincott Williams and Wilkins; 2011.

2. Kemenkes RI. Schizophrenia/psychosis Prevalence Data. (Data Prevalensi Skizofrenia/Psikosis). Jakarta: Kemenkes RI; 2019.

3. Chi MH, Hsiao CY, Chen KC, Lee LT, Tsai HC, Lee IH, et al. The readmission rate and medical cost of patients with schizophrenia after first hospitalization a 10-year follow-up population-based study. Schizophr Res. 2016;170(1):184-90. https://doi.org/10.1016/j.schres.2015.11.025

PMid:26678982 
4. Dewi CR, Marchira R. History of mental disorders in families with recurrence of schizophrenia patients at RSUP Dr. Sardjito Yogyakarta. (Riwayat gangguan jiwa pada keluarga dengan kekambuhan pasien skizofrenia di RSUP $\mathrm{Dr}$ Sardjito Yogyakarta). Ber Kedokt Masy. 2009;25:176-9. https://doi. org/10.22146/db.v2i2.349

5. Liberman RP, Kopelowicz A. Recovery from schizophrenia: A concept in search of research. Psychiatr Serv. 2005;56(6):73542. https://doi.org/10.1176/appi.ps.56.6.735 PMid:15939952

6. Newell K, Gournay R. Mental Health Nursing an Evidencebased Approach. Philadelphia, PA: Churchill Livingstone Elsevier; 2009.

7. CNN Indonesia. The Mental Health Crisis is Draining the Global Economy Until 2030. (Krisis Kesehatan Jiwa Kuras Perekonomian Global Hingga 2030); 2018.

8. Tamizi Z, Fallahi-Khoshknab M, Dalvandi A, MohammadiShahboulaghi F, Mohammadi E, Bakhshi E. Caregiving burden in family caregivers of patients with schizophrenia: A qualitative study. J Educ Health Promot. 2020;9(1):12. https:// doi.org/10.1186/s13643-019-1182-6

PMid:32154307

9. Aubeeluck ND, Luximon-Ramma A. The burdens of family caregivers ofschizophreniain Mauritius. SciMed J.2020;2(3):11831. https://doi.org/10.28991/scimedj-2020-0203-2

10. Fadli SM, Mitra M. Knowledge and expression of family emotions and frequency of schizophrenia recurrences. (Pengetahuan dan ekspresi emosi keluarga serta frekuensi kekambuhan penderita skizofrenia). Kesmas J Kesehat Masy Nas. 2013;7(10):466470. https://doi.org/10.21109/kesmas.v7i10.6

11. Suryani S, Ningsih EW, Nuraeni A. Knowledge, perception, and burden of family in treating patients with schizophrenia who experience relapse. Belitung Nurs J. 2019;5(4):162-8. https:// doi.org/10.33546/bnj.683

12. Rahmani F, Ranjbar F, Hosseinzadeh M, Razavi SS, Dickens GL, Vahidi M. Coping strategies of family caregivers of patients with schizophrenia in Iran: A cross-sectional survey. Int J Nurs Sci. 2019;6(2):148-53. https://doi.org/10.1016/j.ijnss.2019.03.006 PMid:31406884

13. Fitryasari R, Yusuf $A$, Nursalam, Tristiana RD, Nihayati HE. Family members' perspective of family Resilience's risk factors in taking care of schizophrenia patients. Int J Nurs Sci. 2018;5(3):255-61. https://doi.org/10.1016/j.ijnss.2018.06.002 PMid:31406834

14. Dorian M, García JI, López SR, Hernández B. Acceptance and expressed emotion in Mexican American caregivers of relatives with schizophrenia. Fam Process. 2008;47(2):215-28. https:// doi.org/10.1111/j.1545-5300.2008.00249.x

PMid:18605122
15. Stuart GW. Principles and Practice of Psychiatric Nursing. Canada: Mosby Elsevier; 2013.

16. Soundy A, Stubbs B, Roskell C, Williams SE, Fox A Vancampfort D. Identifying the facilitators and processes which influence recovery in individuals with schizophrenia: A systematic review and thematic synthesis. J Ment Heal. 2015;24(2):103-10. https://doi.org/10.3109/09638237.2014.998811

PMid:25643043

17. Jose D, Ramachandra, Lalitha K, Gandhi S, Desai G, Nagarajaiah. Consumer perspectives on the concept of recovery in schizophrenia: A systematic review. Asian J Psychiatr. 2015;14:13-8. https://doi.org/10.1016/j.ajp.2015.01.006 PMid:25703654

18. Febriana B, Susanto W, Rochmawati DH, Setiawati WE. Family support is the key to compliance with the treatment of relapsing schizophrenia patients. J Ners. 2020;15(2):457-61.

19. Pahwa R, Bromley E, Brekke B, Gabrielian S, Braslow JT, Brekke JS. Relationship of community integration of persons with severe mental illness and mental health service intensity. 2014;65(6):822-5. https://doi.org/10.1176/appi.ps.201300233 PMid:24733579

20. Chan KK, Mak WW. The mediating role of self-stigma and unmet needs on the recovery of people with schizophrenia living in the community. 2014;23(9):2559-68. https://doi.org/10.1007/ s11136-014-0695-7

PMid:24756436

21. Sarwono RB, Subandi S. They call me kenthir. (Mereka Memanggilku Kenthir). J Psikol. 2013;40(1):1-14.

22. Liberman RP. Recovery from Disability: Manual of Psychiatric Rehabilitation. Washington, DC: American Psychiatric Publishing Inc.; 2008. p. 628. https://doi.org/10.1176/ps.2009.60.2.270

23. Komala EP, Keliat BA, Wardani IY. Acceptance and commitment therapy and family psycho education for clients with schizophrenia. Enferm. Clín. 2018;28:88-93. https://doi. org/10.1016/s1130-8621(18)30044-5 PMid:29650214

24. Noh C, Choe K, Yang B. Hope from the perspective of people with. Archives. 2008;22(2):69-77.

PMid:18346563

25. Aryanti IG, Aryani LN, Lesmana CB. Correlation of family expressed emotion and frequency of relapse schizophrenia patients. J Clin Cult Psychiatry. 2020;1(2):35-7. https://doi. org/10.36444/jccp.v1i2.15

26. Rashidpour P, Ardekani SM, Abouzari H, Hosseini F, Bidaki R, Abouzari $\mathrm{M}$, et al. The effect of family-expressed emotion on schizophrenia relapse rate 3-Hossein Abouzari 6-Mostafa Abouzari. J Crit Rev. 2019;6(5):252-8. 